\title{
Mapping of nutrition teaching and training initiatives in India: the need for Public Health Nutrition
}

\author{
Shweta Khandelwal ${ }^{*}$, Radhika Dayal, Meenakshi Jha, Sanjay Zodpey and \\ K Srinath Reddy \\ Public Health Foundation of India, ISID 4, Institutional Area, Vasant Kunj, Near the Grand Hotel, \\ New Delhi - 110070, India
}

Submitted 14 March 2011: Accepted 27 September 2011: First published online 25 November 2011

\begin{abstract}
Objective: India spans the spectrum of under- and overnutrition disorders and does so in generous proportions. India also tops the charts globally in the prevalence of risk factors for several chronic diseases. Although Public Health Nutrition (PHN) - both as an academic field as well as a means to improved health - has been around for two centuries in developed countries, it is only now coming to the fore as a conduit for tackling nutrition-related disorders in developing countries. In the light of these issues, we undertook an exercise to map the existing educational initiatives for nutrition, and in particular PHN, in India.

Design: This situational analysis of PHN across India was conducted using a combination of Internet search, telephone calls as well as interviews with experts. Information collected was pooled and tabulated using a snowball approach.

Setting: India.

Subjects: Not applicable.

Results: Currently, there are nearly 190 institutes in India that offer one or more nutrition courses, with the majority offering full-time courses. Of these, PHN was offered in less than five institutes across India and opportunities were confined to specialization options/modules.

Conclusions: This situational analysis reveals the huge gap in existing nutrition ventures and points towards the urgent need to undertake newer academic initiatives especially in the field of PHN in India. Reforms in the education and employment sector need to be brought in which may include working towards making the field of nutrition attractive for career pursuit. The focus of this discipline needs to be broadened to, but not limited to, span the entire spectrum from dietetics to research and teaching. Strong synergistic collaborations and academic partnerships with other developed countries should be encouraged to catalyse finding solutions to emerging and/or existing threats to public health problems.
\end{abstract}

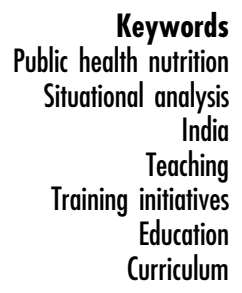

India is experiencing simultaneous demographic, epidemiological, health and nutrition transitions which contribute to a huge chronic disease burden ${ }^{(1)}$. India's status can be perplexing: on one hand, it belongs to the elite group of G13 countries (with an estimated annual income of more than \$US 1 trillion), whereas on the other hand, almost half of its population lives below the poverty line with a daily income of less than \$US 1. India tops (or nearly tops) the charts in the number of people with diabetes as well as being prominent on the world hunger map. Rising obesity in children coexists with the largest number of the world's low-birth-weight babies in India. The complexities of the link between nutrition and chronic diseases have yet to be unravelled ${ }^{(2)}$.

Nutrition, along with four other sub-fields, falls under the core subject area of Home Science. Historically, Home
Science was known as Home Economics which was limited to home and household only, but this has extended in the modern era and now includes interdisciplinary knowledge of wider living environments to understand their impact on the capacities, choices and priorities of individuals and families at all levels, ranging from the household to the local and also the global community ${ }^{(3)}$. Therefore Home Science now comprises five major domains, namely Food and Nutrition, Resource Management, Extension Education, Textiles and Clothing, and Human Development ${ }^{(4)}$.

In recent years, policy makers, donors and implementers have been faced with inadequate evidence relating to diet, nutrition and disease, especially in India. This has constrained the accurate identification of problems and adoption of context-relevant means to achieve desired policy interventions and programme objectives to tackle the rising 
burden of malnutrition as well as chronic diseases. The role of Public Health Nutrition (PHN) is critical in bridging this gap, so as to define pathways and specific actions to apply epidemiological methods to nutrition in terms of methods of data collection, analytical procedures and interpretation of findings. As defined, PHN is the art and science of promoting population health status via sustainable improvements in the food and nutrition system ${ }^{(5)}$. Based upon public health principles, it is a set of comprehensive and collaborative activities, ecological in perspective and intersectoral in scope, including environmental, educational, economic, technical and legislative measures. The recognition of this discipline - in which academics and practitioners converge to understand, share and multiply their efforts to study and combat the nutrition-related disorders in India - is the need of the hour. However, there remains a lack of comprehensive, nationwide education and training programmes for specialists or for the community at large with a primary focus on $\mathrm{PHN}^{(6)}$.

The present paper describes a situational analysis that was undertaken with the aim of examining the current status of PHN teaching and training initiatives in India, with a focus on the variety of courses offered, the capacity for production of PHN specialists as well as status of recognition of the importance of PHN as an academic discipline. The paper also identifies the gap in the current nutrition teaching scenario and highlights the need to work towards undertaking newer academic initiatives in the field of PHN in India.

\section{Experimental methods}

Information regarding the current state of training in nutrition in India was collected using a pragmatic, yet methodical approach. A systematic Internet search (using the search engines Google and Web of Science) was conducted using a set of keywords which included 'nutrition', 'nutrition colleges', 'nutrition institutes', 'public health nutrition', 'home science', 'community nutrition', 'therapeutic nutrition', 'food and nutrition', 'diploma or certificate course in nutrition', 'education initiatives in nutrition' and 'home science universities'. Different combinations of the search keywords using Boolean operators like 'or' and 'and' were used to explore further relevant information. Time (when the institution was formed), language (medium of instruction) and gender (of students) were not controlled for. The search was restricted only to India. The period of search was until November 2010. Two research assistants collected this information individually, hand searched articles/sites which fit our inclusion criteria and later compared the resulting data.

After getting preliminary information on the names of institutes/colleges offering academic degrees in nutrition, detailed information like the contact address, phone numbers, courses, fee structure, batch/class size, eligibility criteria, etc. were obtained from the respective institution's website. The information available through websites was also cross-checked by telephone inquiries. These telephone calls also provided extra information which was not present on the website such as the names of other institutions offering similar courses in that field, course brochure or prospectus availability, etc. The original electronic searches were supplemented by the use of a snowball approach to get further information. The details were compiled and entered into a matrix (see online Appendix 1) developed in Excel 2007 (Microsoft Corporation, Redmond, WA, USA). The information which was not available even after telephone conversations was left blank in the matrix.

A list of various Indian organizations which conduct training programmes or research (but do not offer academic degrees) in the field of nutrition was also prepared using a similar approach. Various experts in the field of nutrition and public health from India were also invited for a WHO-funded 'Expert Group National Consultation' on PHN curriculum designing. The discussion contents and information from the experts regarding teaching and training activities in this field were also duly incorporated.

\section{Results}

The various academic levels at which Nutrition as a subject is offered ranged from Certificate courses, Bachelors (BSc) and Masters (MSc), to postgraduate (PG) Diploma and Doctorate $(\mathrm{PhD})$ programmes (see online Appendix 1). There are currently 190 institutes in India that offer one or more of these nutrition courses, mostly as full-time courses (Fig. 1). Common sub-fields/specializations under the broad Nutrition umbrella are Food Science and Nutrition, Food Technology, Therapeutic/ Clinical Nutrition, Community Nutrition, Food Science and Quality Control, Human Nutrition and Dietetics, Nutrition and Health Education, and Nutrition and Child Care. The most common sub-field is Food and Nutrition, offered by $\sim 61.6 \%$ ( $n$ 117) of the nutritional academic institutes all over India. Approximately half of the nutrition academic institutes were situated in South India $(42 \cdot 6 \%$; $n$ 81) and their focus was largely on Food Science and Technology courses (Fig. 1). The field of nutrition was found to be hugely gender biased, with mostly women students and teachers seen across all institutions surveyed.

The courses were taught mostly in two ways: (i) classroom teaching (also known as the regular mode); and (ii) distance learning. Distance education could be further divided into three types: (i) totally online - completely over the Internet, no face-to face class; (ii) hybrid - part of the course online, part face-to-face; and (iii) web-enhanced face-to-face class with online component (http://www. fldlc.org/taskforce/pdf/toward_definition.pdf). The mode of delivery for the nutrition courses included: regular ( $n$ 169); distance learning ( $n$ 14); both regular and distance 


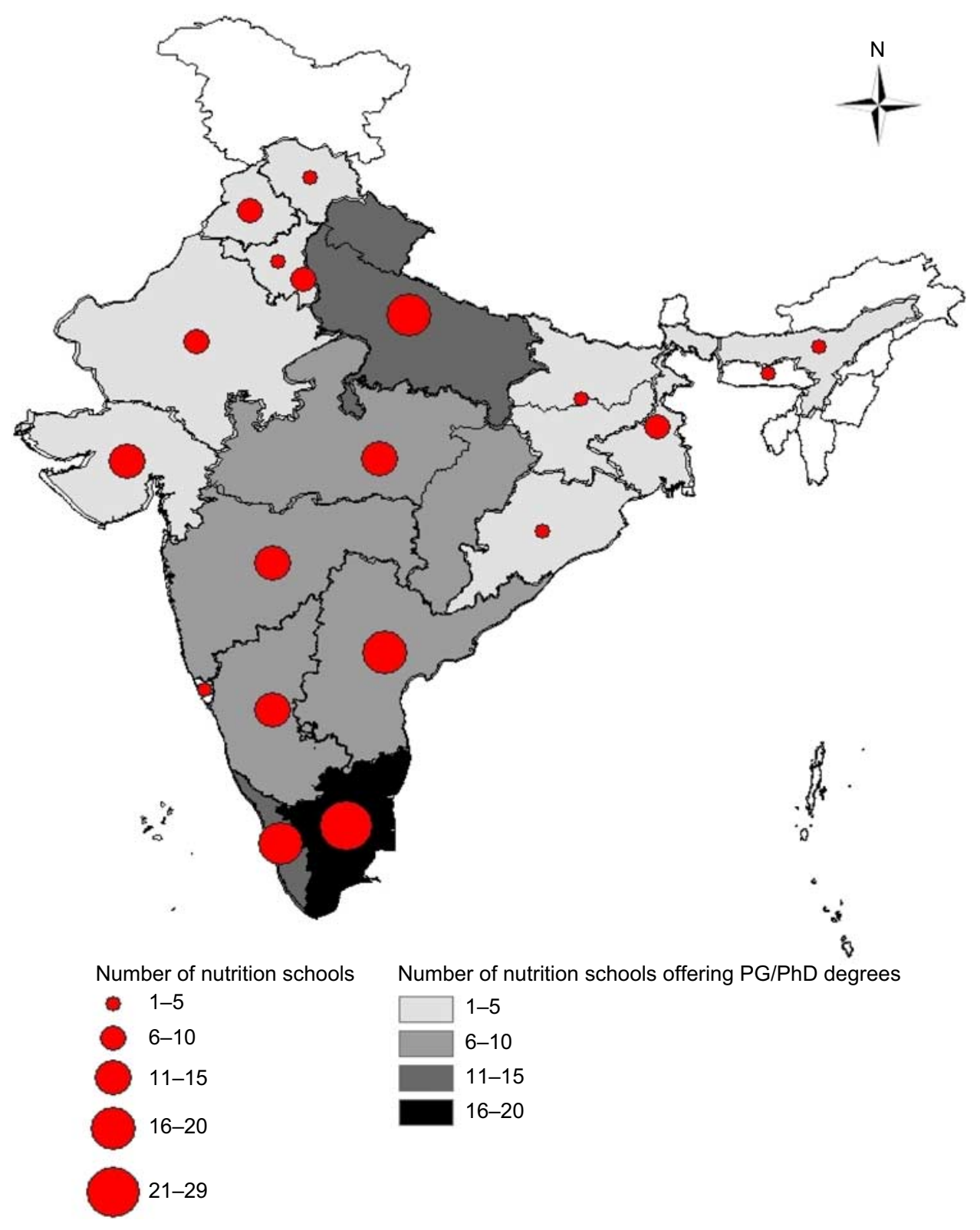

Fig. 1 (colour online) Distribution of nutrition schools by state and type of degree offered (PG, postgraduate)

learning $(n$ 7). Different courses on nutrition in India varied in duration for each level. In its conventional form, the Bachelors degree is usually obtained in 3 years, Masters in 2 years; Certificate and Diploma courses vary between 6 months and 2 years, while MPhil courses are usually for 1 year. A PhD programme can usually be completed in a minimum of 3 years (duration depends on several factors like topic selected, research depth, facilities and resources available). The eligibility criteria for the courses varied as per the colleges and degrees. The criteria for selecting candidates for Bachelors degree in most of the colleges was $10+2$ with Science as the major, whereas those with MBBS, BSc (Nutrition or Home Science) were eligible to apply for post-graduation in Nutrition. Individuals with a
$10+2$ degree in Science could apply for Certificate courses in Nutrition (Table 1).

PHN did not emerge as an independent discipline in any college/university across India. However, a 1-year Diploma programme in Dietetics and PHN was offered (regular mode) by three colleges in North India. The fee range for the complete Diploma course is Rs 31000-35000 ( \$US 700-750). Three institutes offered post-graduation and one offered a Doctoral degree in Food and Nutrition with PHN as the specialization track. A few of the universities ( $n$ 4) offered PHN as one of the electives to students during graduation and post-graduation. This reiterates/exposes the fact that India lacks dedicated educational initiatives for PHN. 
Table 2 lists the various Indian organizations which conduct short-term training programmes or research in the field of nutrition but do not offer academic degrees.

\section{Discussion}

The current scenario offers both challenges and opportunities for nutritional scientists and public health practitioners. It is evident from the findings of the present situational analysis that, despite a health profile which suggests necessary PHN interventions, India severely lacks dedicated education and training programmes in PHN. As explained above, a minuscule fraction (0.02\%; $n 4$ ) of the institutions offered PHN - and that too only in a cursory fashion (as electives or track options). Issues inherent to the management and treatment of chronic lifestyle diseases such as physical activity, diet and access to appropriate standards of care have also been grossly neglected. Recognizing PHN as a subject in its own right may help to create a nutrition workforce who could in turn contribute to address concerns like undernutrition and rising obesity in $\operatorname{India}^{(7)}$. PHN has a distinct/unique identity, incorporating the relevant aspects of the variety of disciplines that bear on the nutrition problem, as well as incorporating scientific advances in the understanding of nutritional problems ${ }^{(8)}$.

India allocated a mere $3 \cdot 2 \%$ of its Gross Domestic Product to the education sector in $2010^{(9)}$. The lack of resources and attention to develop/promote educational endeavours in PHN in developing countries needs stronger publicity of the fact that this discipline can positively affect nutritional practices of the community, as well as improve the delivery of high-quality nutrition care $^{(10)}$. Further, the implementation of national nutrition programmes also needs sustained institutional commitment as well as human and financial resources.

The success of the implementation of these programmes is determined by the quality and adequacy of numbers of trained and motivated professionals available nationally. Hence, the development of quality training programmes that can cater to the numerical needs of personnel who have the necessary skills and competencies to implement these programmes becomes a cornerstone of such national endeavours. The development of human resources for planning and implementing food and nutrition programmes to address the needs of communities in the developing world requires a problem-oriented, integrated approach. Finally, programmes conforming to common standards for education, training and quality assurance are the need of the hour, as the implementation of populationbased strategies that are efficient and yield desired results needs a skilled and dedicated workforce ${ }^{(11)}$. A task of this magnitude requires concerted efforts of the different groups and stakeholders involved and, most importantly, a comprehensive workforce capacity equipped to address the 
Table 2 List of Indian institutes offering research or short-term training in Nutrition

\begin{tabular}{|c|c|c|c|}
\hline Name & City & State & Website \\
\hline All India Institute of Hygiene \& Public Health & Kolkata & West Bengal & www.aiihph.gov.in \\
\hline All India Institute of Medical Sciences & Delhi & Delhi & www.aiims.ac.in \\
\hline $\begin{array}{l}\text { Association of Food Scientists \& Technologists in } \\
\text { India }\end{array}$ & Mysore & Karnataka & www.afsti.in \\
\hline $\begin{array}{l}\text { Department of Science \& Technology, Ministry of } \\
\text { Science \& Technology }\end{array}$ & Delhi & Delhi & www.dst.gov.in \\
\hline Food Science \& Nutrition Academy & Kottayam & Kerala & www.fsnaindia.com \\
\hline Home Science Association of India & Kerala & Kerala & $\begin{array}{l}\text { www.avinashilingam.edu/ } \\
\text { association.htm }\end{array}$ \\
\hline Indian Dietetic Association & - & - & www.idaindia.com \\
\hline Indian Science Congress & Kolkata & West Bengal & www.sciencecongress.nic.in \\
\hline Institute of Health System & Hyderabad & Andhra Pradesh & www.ihs.org.in/ \\
\hline International Food Policy Research Institute & Delhi & Delhi & www.ifpri.org \\
\hline International Life Sciences Institute & Delhi & Delhi & www.ilsi-india.org \\
\hline Kovai Medical Centre Research \& Educational Trust & Coimbatore & Kerala & www.kmch.ac.in \\
\hline M.S. Swaminathan Research Foundation & Chennai & Tamil Nadu & www.mssrf.org \\
\hline Nutrition Foundation of India & Delhi & Delhi & www.nutritionfoundationofindia.res.in \\
\hline Nutrition Society of India & Hyderabad & Andhra Pradesh & www.nutritionsocietyindia.org \\
\hline
\end{tabular}

complex issues underlying all nutritional disorders. In order to successfully tackle these challenges, a paradigm shift is needed in the way the agenda of nutrition curriculum and nutrition research is handled in India. This needs systematic, rigorous and methodical research and analytical skills which are urgently required to strengthen the PHN cadre in India.

Specific skills often are provided best through short courses, certificate programmes, workshops and in-service training. Short-term programmes are the best medium for initiating and implementing innovative approaches, such as distance learning, courses on the Internet (online teaching), and the provision of continuing education intermittently to a group of nutrition leaders over a prolonged period of time. Short-duration academic courses like diploma programmes, certificate courses, etc. are flexible, emphasize experiential learning and are more responsive to changing nutritional needs and problems. In addition, these value-addition courses are less restricted by conventional bureaucratic and academic barriers $^{(12)}$. Tailoring online educational initiatives to the needs of the developing countries and providing recognition/certification will enhance the skill set of many professionals who may otherwise be limited due to geographical barriers and lack of expert guidance as well as quality education $^{(7)}$.

Trained professionals in PHN can join the pool of public health professionals armed with the added value of training in nutrition epidemiological research methods, food science and nutrition principles. They have the potential to hold key positions in local, national and international organizations such as non-governmental organizations, district- and state-level health systems, medical colleges, the pharmaceutical sector, government-run programmes like the Integrated Child Development Scheme and the National Rural Health Mission, UN organizations, regional WHO offices and other international organizations committed to the cause of public health nutrition. Unfortunately, more than $90 \%$ of Masters and Doctoral candidates in nutrition from India work on projects or teach at the home science colleges; there is a lack of research environment, facilities and funding to undertake meaningful nutrition research which would be of public health importance ${ }^{(7)}$.

The establishment of training and educational initiatives for professionals in the field would also help to develop quality and research-based programmes focusing and specializing in $\mathrm{PHN}^{(13)}$. However, it is also important to sensitize policy makers towards the need and importance of studying PHN as an independent discipline ${ }^{(14)}$. Nutrition teaching programmes serve as the initiators of building research skills which in turn help to influence policy. People at the policy level can make a big difference if they understand the nutritional implications of the range of policy decisions. Thus, a comprehensive effort in public nutrition would need to address appropriate teaching and training of a critical mass of key individuals at each level of a country. It needs to emphasize the three As - awareness, access and affordability. Such a programme which takes all three As into account could achieve significant improvement in nutrition and create the human and institutional capabilities to sustain positive nutritional gains.

\section{Acknowledgements}

The study was funded by the WHO-India office, New Delhi. There are no conflicts of interest. S.K., S.Z., K.S.R. designed the study and wrote the manuscript; R.D. and M.J. collected the data and extracted the information. All authors have read and approved the manuscript. The authors thank Mohammed K. Ali (Assistant Professor, Hubert Department of Global Health Emory University, Atlanta, GA, USA), Mark Huffman (Assistant Professor, North Western University, Chicago, IL, USA), Mary-Beth Weber (PhD student, Emory University) and Sandeep Kishore 
(Medical Scientist Training Program Fellow, Weill Cornell/ The Rockefeller University/Sloan-Kettering Institute, New York, NY, USA) for reading the manuscript and providing valuable and insightful feedback. Special thanks to Ms Karen Siegel, doctoral student at Emory University, who helped in mapping the nutrition institutions in the manuscript.

\section{References}

1. Thankappan KR, Shah B, Mathur P et al. (2010) Risk factor profile for chronic non-communicable diseases: results of a community based study in Kerala, India. Indian J Med Res 131, 53-63.

2. Yajnik CS \& Ganpule-Rao AV (2010) The obesity-diabetes association: what is different in Indians? Int J Low Extrem Wounds 9, 113-115.

3. Kamaswaran J (2004) History of Home Science in India, 1st ed. Chennai: Tamil Nadu Textbook Corporation.

4. Lichtenstein AH \& Ludwig DS (2010) Bring back home economics. JAMA 303, 1857-1858.

5. Hughes R \& Somerset S (1997) Definitions and conceptual frameworks for public health and community nutrition: a discussion paper. Aust J Nutr Diet 54, 40-45.
6. Beaudry M, Hamelin AM \& Delisle H (2004) Public Nutrition: an emerging paradigm. Can J Public Health 95, 375-377.

7. Sazawal S, Hiremath GS 2006. Nutrition research and capacity building in India. In Proceedings of the International Symposium on Building Leadership Skills in Food and Nutrition Essential for National Development. Mysore, India, 23-25 June 2006, pp. 16-22. Mysore: Central Food Technological Research Institute.

8. Rogers BL \& Schlossman NP (1997) Public nutrition: the need for cross-disciplinary breadth in the education of applied nutrition professionals. Food Nutr Bull 18, 120-133.

9. Central Intelligence Agency (2010) The World Factbook. South Asia: India. https://www.cia.gov/library/publications/ the-world-factbook/geos/in.html (accessed January 2011).

10. Egan MC (1994) Public health nutrition: a historical perspective. J Am Diet Assoc 94, 298-304.

11. Pérez-Escamilla R \& King J (2007) Evidence-based public nutrition: an evolving concept. J Nutr 137, 478-479.

12. Winterfeldt EA \& Ebro LL (2005) Dietetics: Practice \& Future Trends. Sudbury, MA: Jones \& Barlett.

13. Khandelwal S, Huffman M, Shah S et al. (2011) Noncommunicable, chronic disease training and education needs in India: perspectives from young professionals. Global Heart 6, 195-199.

14. Pandav CS (2010) Role of faculty of medical college in national health policy and program development. Indian J Community Med 35, 3-6. 